\title{
Smokeless tobacco consumption in a multi-ethnic community in Pakistan: a cross-sectional study
}

\author{
S.M. Abbas, ${ }^{1}$ A. Y. Alam, ${ }^{2}$ M. Usman ${ }^{7}$ and K. Siddiqi ${ }^{3}$
}

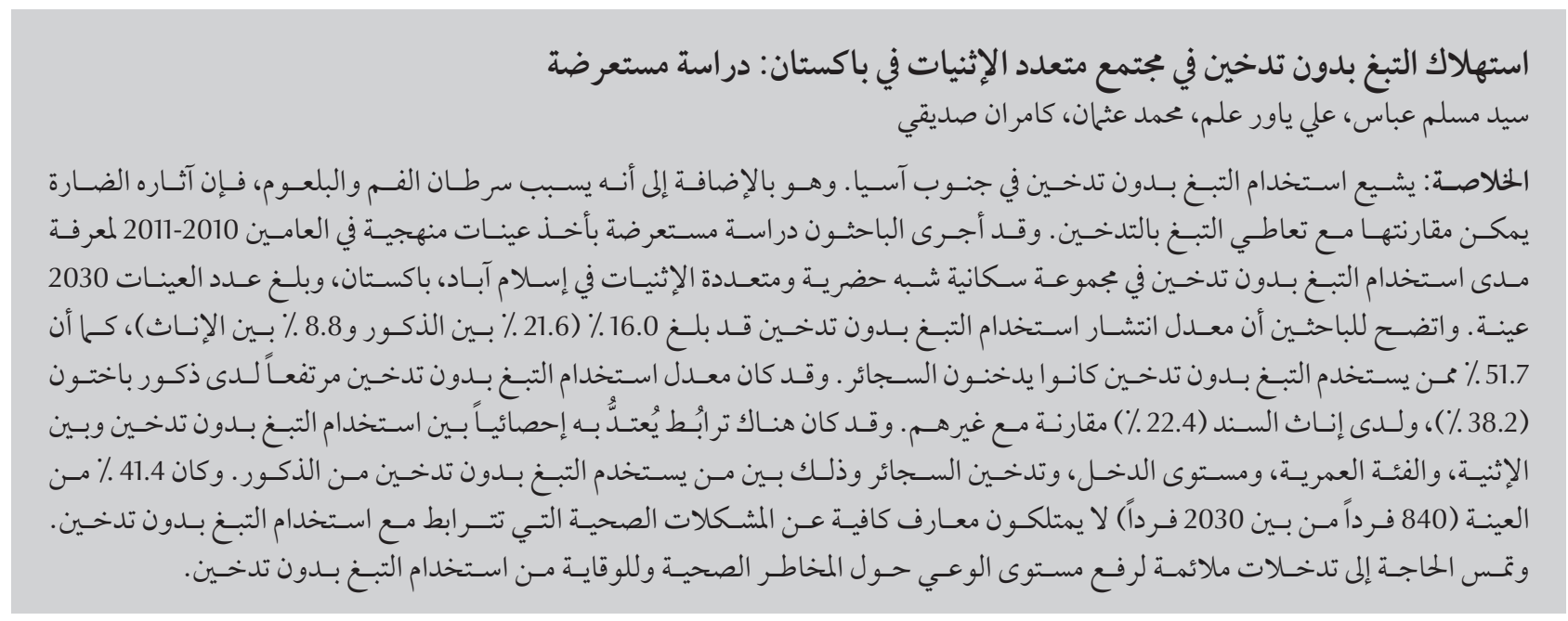

ABSTRACT Smokeless tobacco is commonly used in south Asia. In addition to causing oral and pharyngeal cancers, its harmful effects are comparable to smoking tobacco. A cross-sectional survey with systematic sampling was conducted in 2010-2011 to investigate smokeless tobacco use in a multi-ethnic, semi-urban population in Islamabad, Pakistan $(n=2030)$. The prevalence of smokeless tobacco use was $16.0 \%(21.6 \%$ among males and $8.8 \%$ among females); $51.7 \%$ of smokeless tobacco users were also cigarette smokers. The rate of smokeless tobacco use was comparatively high among Pakhtun males (38.2\%) and Sindhi females (22.4\%). The associations between smokeless tobacco use and ethnicity, age group, income level and cigarette smoking were statistically significant among male smokeless tobacco users. Of the sample 41.4\% (840/2030) had inadequate knowledge about the health problems associated with smokeless tobacco. Appropriate interventions are needed to raise awareness of the health risks and to prevent smokeless tobacco use.

\section{Consommation de tabac sans fumée dans une communauté pluriethnique au Pakistan : une étude transversale}

RÉSUMÉ La consommation de tabac sans fumée est courante en Asie du Sud. Outre les cancers de la cavité buccale et du pharynx, ses effets nocifs sont comparables à ceux de la consommation de tabac à fumer. Une enquête transversale à partir d'un échantillonnage systématique $(n=2030)$ a été menée en 2010 et 2011 afin d'évaluer la consommation de tabac sans fumée dans une population semi-urbaine et pluriethnique à Islamabad (Pakistan). La prévalence de la consommation de tabac sans fumée était de 16,0 \% (21,6 \% chez les hommes et 8,8 \% chez les femmes) ; 51,7 \% des consommateurs de tabac sans fumée étaient aussi des fumeurs de cigarettes. Le pourcentage de consommation de tabac sans fumée était comparativement élevé chez les hommes pachtounes (38,2\%) et les femmes sindhies (22,4\%). Les associations entre la consommation de tabac sans fumée, le groupe ethnique, la tranche d'âge, le niveau de revenu et la consommation de cigarettes étaient statistiquement significatives chez les consommateurs de tabac sans fumée de sexe masculin. Au sein de l'échantillon, 41,4 \% (840/2030) possédaient des connaissances insuffisantes sur les problèmes de santé liés au tabac sans fumée. Des interventions appropriées sont nécessaires pour sensibiliser aux risques sanitaires et prévenir la consommation de tabac sans fumée. 


\section{Introduction}

Smokeless tobacco products, which are not burnt but are utilized orally or nasally, have been used in different countries for centuries and are accessible in many different forms $(1,2)$. The prevalence of smokeless tobacco consumption varies across and within different countries, depending on factors such as socioeconomic status, ethnic origin, sex and age $(1,3)$. These products are most commonly used by south Asian communities, in which around one-third of tobacco is consumed in smokeless form (2). Smokeless tobacco consumption is a threat to public health. It is associated with oropharyngeal, laryngeal, oesophageal and pancreatic cancers, cardiovascular diseases, adverse outcomes of pregnancy and dental disease (4). Furthermore, studies indicate that the use of smokeless tobacco products appears to be increasing, particularly among the younger age groups (5-7).

The consumption of smokeless tobacco products in low- and middle-income countries is of particular concern because the products are manufactured and sold without proper regulation and are often consumed with other carcinogenic substances (2). In Pakistan, a lowincome country, smokeless tobacco is consumed mainly in the form of naswar (tobacco flavoured with cardamom and menthol) (2), paan or betel quid (containing tobacco, lime, areca nut and other flavourings) (8). Despite its widespread use in Pakistan, little empirical research has been carried out on the prevalence and determinants of smokeless tobacco consumption. Studies about the association of use of smokeless tobacco and other substances, such as areca nut, with head and neck and oral cancers have been conducted in certain regions of Pakistan, often with a small sample size (8-14). Similarly, a study in Karachi reported a $16 \%$ prevalence of smokeless tobacco use among 772 adolescent high-school males (10). The prevalence of smokeless tobacco use among various ethnic groups and their knowledge and perceptions concerning to its health implications is not known. We investigated these factors in a semi-urban population in Nurpur Shahan in the outskirts of Islamabad. The population is approximately 14000 , consisting of people who are migrants from all provinces and represent different ethnic groups and sociocultural backgrounds

\section{Methods}

A cross-sectional survey with systematic random sampling was conducted from January 2010 to January 2011 . We measured self-reported use of smokeless tobacco, types of products used and individuals' perceptions and knowledge of the related health implications.

\section{Study setting}

Nurpur Shahan was selected as the surveillance site. This urban slum was chosen because it has settlements from all provinces and represents a relatively marginalized segment of the society.

\section{Sampling}

The sample was first stratified into males and females. With a precision of $+3 \%$, and an expected prevalence of smokeless tobacco of $50 \%$ in the community and $95 \%$ confidence interval (CI), the sample size was estimated as 992 in each group (males and females). To account for possible incomplete data, the sample size was increased to 1015 each, a total of 2030. The sample size was inflated by only $2.3 \%$, because the interviewers were well trained, as pilot-testing further strengthened the rigorous methodology and because the interviews were conducted face-to-face, ensuring completeness of questionnaires.

Males and females aged 5-65 years who were permanent residents of the area and gave informed consent were included in the study. Children aged 5 years and above were included in the study because previous studies conducted in South Asian communities has reported smokeless tobacco use in the age range of 5-10 years $(15,16)$.

A systematic sampling technique was applied. In each street of the locality, we surveyed the first house followed by the third, fifth and so on. When a particular street was completed, subsequent streets was approached in a similar fashion. The study was conducted by groups of 4 students, each including at least 1 female, as per the cultural norms of the community. Once a house was selected all members of the family that met the eligibility criteria were consented and then interviewed.

\section{Data collection}

\section{Questionnaire}

The questionnaire components were compiled utilizing previously validated questions. The questionnaire included 3 sections. The first section was to determine the following sociodemographic variables: age (from date of birth or, if unavailable, estimation of age with reference to an index event) (17,18); education (number of years of formal education completed) (17-19); ethnicity (determined from place of birth and ethnic origin in Pakistan) (20); and income (as rupees per month) $(17,18)$. The second section enquired about respondents' tobacco consumption: type of smokeless tobacco products used; amount and frequency of use; and cigarette smoking habits. Smokers were define as current and ever-smokers $(8-12,15-20)$. In the third section respondents answered 5 questions designed to assess their knowledge and perceptions about the health implications associated with smokeless tobacco use (8-12,15-20).

The questionnaire was first pilottested in a few households to address any ambiguity. The questions was translated into Urdu language and then back-translated into English to ensure content validity. 


\section{Training of the interviewers}

The survey was carried out by trained undergraduate medical students as part of their scheduled public health practice field visits. Eight teams, each consisting of 4 students, administered the survey. The students had prior experience of conducting surveys in the same community. The students were formally trained in taking informed consent, administering the questionnaire in accordance with the Strengthening the Reporting of Observational Studies in Epidemiology checklist for conducting cross-sectional studies (21).

\section{Interviews}

The survey questionnaire was administered through face-to-face interviews. A non-coercive approach was adopted, and the participants were not offered any incentives to participate in the survey. Illiterate respondents were given a verbal explanation about the purpose of the research, and informed consent was taken; they were asked to give a thumbprint if they could not sign. A quality assurance framework was used to ensure consistency and quality (22). Moreover, verification checks were done on $5 \%$ of the sample (17). The response rate of the survey was $99 \%$.

\section{Ethical considerations}

Ethical clearance for this study was obtained from the ethics committee at Shifa College of Medicine in December 2009. Written informed consent was obtained from all participants in the survey and all data collected were kept confidential. In the case of children (5-13 years old) informed consent was taken from adults in the household.

\section{Data analysis}

The data were entered into SPSS, version 19.0 statistical software. All categorical variables were presented as frequencies and percentages. The relationship between 2 categorical variables was calculated by cross-tabulation and applying chi-squared test and estimating $P$-values.

\section{Results}

A total of 2030 individuals were surveyed including 1132 (55.8\%) males and 898 (44.2\%) females. The prevalence of smokeless tobacco use in the total sample was $16.0 \%(324 / 2030)$ : $21.6 \%(245 / 1132)$ among males and $8.8 \%(79 / 898)$ among females. The rate of tobacco smoking among male smokeless tobacco users was 188/245 (76.7\%) and among female smokeless tobacco users was $49 / 79$ (62.0\%). Of the participants 54 (2.6\%) reported being daily consumers of paan mixed with tobacco and $84(4.1 \%)$ as daily naswar users (Figure 1).

Analysis by ethnic groups showed the highest prevalence of smokeless tobacco use was among Sindhi (23.9\%) followed by Pakthtun (22.3\%), with Punjabi (12.3\%) and Urdu speaking (16.0\%) groups reporting the lowest prevalence (Table 1 ). The prevalence of smokeless tobacco use was highest in the age group 30-39 years (23.6\%). Furthermore, smokeless tobacco use was highest among male users in age groups 11-20 years (38.4\%) whereas among females it was highest in ages $50+$ years. The prevalence of smokeless tobacco was lowest among the participants earning 9000+ rupees per month and those with the highest level of education.
The association between smokeity, income level and cigarette smoking was statistically significant $(P<0.001)$ among male smokeless tobacco users (Table 2). Among female smokeless tobacco users there was a significant association between smokeless tobacco use and income level, education and ethnicity. In the total sample education was the only variable that was not significant $(P=0.06)$.

Nearly half (41.4\%) of the study sample had inadequate knowledge about the health problems associated with smokeless tobacco and $34.1 \%$ of the sample perceived smokeless tobacco use as harmless. Only 15 (0.7\%) participants suspected an association of cardiovascular disease with smokeless tobacco use and even fewer (0.4\%) reported an association of smokeless tobacco with adverse outcomes of pregnancy (Table 3).

\section{Discussion}

Smokeless tobacco is an important public health concern in south Asian countries, as such products are manufactured the carcinogenic content of the products and information to the public about their harmful health effects (2). The consumption of smokeless tobacco less tobacco use and age group, ethnicat a mass scale without any checks on
Paan

Naswar

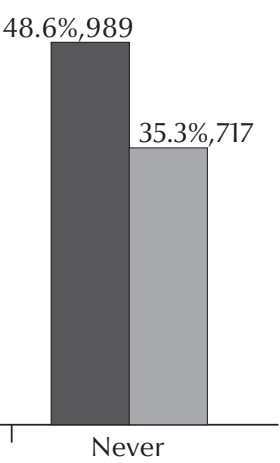

or more a week

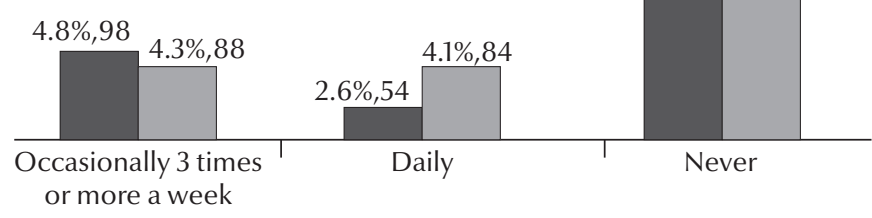

Figure 1 Respondents' self-reported frequency of use of different smokeless tobacco products $(n=2030)$ 


\begin{tabular}{|c|c|c|c|c|c|c|c|c|c|c|c|c|}
\hline \multirow[t]{3}{*}{ Variable } & \multicolumn{4}{|c|}{ Both sexes } & \multicolumn{4}{|c|}{ Males } & \multicolumn{4}{|c|}{ Females } \\
\hline & \multirow{2}{*}{$\begin{array}{l}\text { Total } \\
\text { No. }\end{array}$} & \multicolumn{3}{|c|}{ Smokeless tobacco users } & \multirow{2}{*}{$\begin{array}{c}\text { Total } \\
\text { No. }\end{array}$} & \multicolumn{3}{|c|}{ Smokeless tobacco users } & \multirow{2}{*}{$\begin{array}{l}\text { Total } \\
\text { No. }\end{array}$} & \multicolumn{3}{|c|}{ Smokeless tobacco users } \\
\hline & & No. & $\%$ & $95 \% \mathrm{Cl}$ & & No. & $\%$ & $95 \% \mathrm{CI}$ & & No. & $\%$ & $95 \% \mathrm{Cl}$ \\
\hline Overall & 2030 & 324 & 16.0 & 14.3-17.5 & 1132 & 245 & 21.6 & $19.2-24.0$ & 898 & 79 & 8.8 & $7.0-11.0$ \\
\hline \multicolumn{13}{|l|}{ Age (years) } \\
\hline $5-10$ & 269 & 13 & 4.8 & $2.3-7.4$ & 159 & 10 & 6.3 & $2.5-10.0$ & 110 & 3 & 2.7 & $0.3-5.7$ \\
\hline $11-20$ & 388 & 81 & 20.9 & $16.8-24.8$ & 185 & 71 & 38.4 & $31.3-45.3$ & 203 & 10 & 4.9 & $1.9-7.8$ \\
\hline $21-29$ & 442 & 84 & 19.0 & $15.3-22.7$ & 267 & 62 & 23.2 & $18.1-28.3$ & 175 & 22 & 12.6 & 7.7-17.5 \\
\hline 30-39 & 246 & 58 & 23.6 & 18.3-28.9 & 147 & 48 & 32.7 & $25.0-40.2$ & 99 & 10 & 10.1 & $4.2-16.0$ \\
\hline $40-49$ & 383 & 42 & 11.0 & $7.8-14.0$ & 204 & 25 & 12.3 & $7.8-16.8$ & 179 & 17 & 9.5 & 5.2-13.8 \\
\hline $50-59$ & 200 & 29 & 14.5 & $9.6-19.4$ & 115 & 18 & 15.7 & $8.9-22.2$ & 85 & 11 & 12.9 & $5.8-20.0$ \\
\hline$>60$ & 102 & 17 & 16.7 & $9.4-23.8$ & 55 & 11 & 20.0 & $9.4-30.6$ & 47 & 6 & 12.8 & $3.2-22.2$ \\
\hline \multicolumn{13}{|l|}{ Ethnicity } \\
\hline Punjabi & 1127 & 139 & 12.3 & $10.4-14.2$ & 612 & 102 & 16.7 & 13.6-19.5 & 515 & 37 & 7.2 & $4.9-9.4$ \\
\hline Pakhtun & 452 & 101 & 22.3 & $18.5-26.1$ & 228 & 87 & 38.2 & $31.8-44.4$ & 224 & 14 & 6.3 & $3.1-9.5$ \\
\hline Sindhi & 134 & 32 & 23.9 & $16.6-31.0$ & 85 & 21 & 24.7 & $15.5-33.8$ & 49 & 11 & 22.4 & $10.7-34.1$ \\
\hline Balochi & 44 & 9 & 20.5 & $8.5-32.3$ & 30 & 7 & 23.3 & $8.2-38.4$ & 14 & 2 & 14.3 & $4.1-32.5$ \\
\hline Urdu speaking & 162 & 26 & 16.0 & $10.4-21.6$ & 103 & 16 & 15.5 & $8.5-22.5$ & 59 & 10 & 16.9 & $7.3-26.5$ \\
\hline Other & 111 & 17 & 15.3 & $8.6-22.0$ & 74 & 12 & 16.2 & $7.8-24.6$ & 37 & 5 & 13.5 & $2.5-24.5$ \\
\hline \multicolumn{13}{|l|}{$\begin{array}{l}\text { Income per } \\
\text { month (rupees) }\end{array}$} \\
\hline$<2000$ & 288 & 49 & 17.0 & $12.1-21.8$ & 90 & 21 & 23.3 & $14.6-32.0$ & 198 & 28 & 14.1 & $9.2-18.9$ \\
\hline 2000-3499 & 389 & 65 & 16.7 & $12.9-20.4$ & 96 & 60 & 62.5 & $52.8-72.2$ & 293 & 5 & 1.7 & $0.2-3.2$ \\
\hline $3500-4999$ & 470 & 78 & 16.6 & 13.2-19.9 & 184 & 49 & 26.6 & $20.2-32.9$ & 286 & 29 & 10.1 & $6.6-13.6$ \\
\hline 5000-8999 & 629 & 117 & 18.6 & $15.6-21.6$ & 525 & 101 & 19.2 & $15.8-22.6$ & 104 & 16 & 15.4 & $8.4-22.2$ \\
\hline $9000+$ & 254 & 15 & 5.9 & $3.0-8.8$ & 237 & 14 & 5.9 & $2.9-8.9$ & 17 & 1 & 5.9 & $0.31-16.9$ \\
\hline \multicolumn{13}{|l|}{ Education } \\
\hline None & 1048 & 178 & 17.0 & $14.6-19.2$ & 392 & 129 & 32.9 & $28.2-37.5$ & 656 & 49 & 7.5 & $5.4-9.4$ \\
\hline Primary & 227 & 39 & 17.2 & $12.2-22.0$ & 178 & 29 & 16.3 & $10.8-21.7$ & 49 & 10 & 20.4 & $9.1-31.7$ \\
\hline Middle & 267 & 45 & 16.9 & $12.3-21.3$ & 159 & 39 & 24.5 & $17.8-31.2$ & 108 & 6 & 5.6 & $1.2-9.8$ \\
\hline Matric & 185 & 32 & 17.3 & $11.8-22.7$ & 125 & 26 & 20.8 & $13.7-27.9$ & 60 & 6 & 10.0 & $2.4-17.6$ \\
\hline Intermediate & 135 & 16 & 11.9 & $6.4-17.2$ & 119 & 9 & 7.6 & $2.8-12.4$ & 16 & 7 & 43.8 & $19.4-68.0$ \\
\hline $\begin{array}{l}\text { Graduate and } \\
\text { above }\end{array}$ & 168 & 14 & 8.3 & $4.1-12.5$ & 159 & 13 & 8.2 & $3.9-12.5$ & 9 & 1 & 11.1 & $0.4-31.6$ \\
\hline \multicolumn{13}{|l|}{$\begin{array}{l}\text { Cigarette } \\
\text { smoking }\end{array}$} \\
\hline Smoker & 458 & 237 & 51.7 & $47.1-56.3$ & 395 & 188 & 47.6 & $42.7-52.5$ & 63 & 49 & 77.8 & $67.4-87.9$ \\
\hline Non-smoker & 1572 & 87 & 5.5 & $4.4-6.6$ & 737 & 57 & 7.7 & $5.8-9.6$ & 835 & 30 & 3.6 & $2.3-4.9$ \\
\hline
\end{tabular}

$\mathrm{Cl}=$ confidence interval .

among males in the study is comparable to the rates observed in India (26.4\%) according to the Global Adult Tobacco Survey (GATS) household survey (23). However, consumption among females was much lower than the rate observed in Indian (18.4\%) and Bangladeshi (27.9\%) females (23). When compared with the Global Youth Tobacco Survey (GYTS) conducted in Pakistan the prevalence among male smokeless tobacco users in the study sample exceeded the rate (13.8\%) among male users surveyed in the GYTS, whereas among female users it was similar (7.4\%) (24). Smokeless tobacco use started at an early age in our population, and this is similar to the studies conducted in 3 different rural areas of India and the state of Goa $(15,16)$.

Paan mixed with tobacco and naswar were found to be the 2 commonest types of smokeless tobacco products used, and this agrees with previous 


\begin{tabular}{|c|c|c|c|c|c|c|}
\hline \multirow[t]{3}{*}{ Variable } & \multicolumn{6}{|c|}{ Significance of association with smokeless tobacco use } \\
\hline & \multicolumn{2}{|c|}{ Total } & \multicolumn{2}{|c|}{ Males } & \multicolumn{2}{|c|}{ Females } \\
\hline & $x^{2}$ & $P$-value & $x^{2}$ & $P$-value & $x^{2}$ & $P$-value \\
\hline Age & 53 & 0.001 & 59.3 & 0.001 & 11.5 & 0.07 \\
\hline Ethnicity & 31.7 & 0.001 & 34.7 & 0.001 & 10.9 & 0.05 \\
\hline Education & 10.5 & 0.06 & 9.15 & 0.103 & 11.5 & 0.04 \\
\hline Income & 23.0 & 0.001 & 31.2 & 0.001 & 51.1 & 0.001 \\
\hline Cigarette smoking & 607 & 0.001 & 111.3 & 0.001 & 5.2 & 0.02 \\
\hline
\end{tabular}

findings from Pakistan (11-13). The consumption of naswar (53.0\%) can be explained by the presence of a Pakthun and Balochi ethnic groups in the sample who have a cultural tradition of using this product $(12,13)$.

The association between education level and smokeless tobacco use was not significant in the total sample $(P$ $=0.06)$; however, nearly half of our sample consisted of people with no formal education and the sample size was therefore insufficient to detect associations within other categories. The rate of smokeless tobacco consumption fell to $8.3 \%$ when education levels increased to graduate and above, a finding similar to a study conducted in Rawalpindi, Pakistan (17). The low level of awareness among our participants about the health implications associated with smokeless tobacco highlights the need for health education campaigns to raise awareness in the community.
This was not a countrywide survey using a sampling strategy that was representative of the whole Pakistan population. Instead, the study was conducted in a diaspora population representing major ethnicities living in the country. Education and income levels in the community differ from those in the urban cities and the associations between smokeless tobacco and socioeconomic factors may vary if cross-sectional studies with a representative sample size were conducted there. However $66 \%$ of the Pakistani population lives in rural areas (25) and the education and income levels in this community study may correspond with the rural population of Pakistan. The awareness levels regarding the health implications associated with smokeless tobacco may also be different in the urban cities where education levels are higher and people have more access to information in the form of social and electronic media.
The consumption of smokeless tobacco at an early age and high prevalence among particular ethnicities suggests that there may be a cultural acceptance of the habit among this urban slum community. This may also be influenced by level of education and awareness about the health implications associated with smokeless tobacco. Smokeless tobacco use is culturally embedded within South Asian communities (2). Furthermore, it will be worthwhile focusing future research on the ethnic and cultural context. Information about the health implications associated with smokeless tobacco use need to be more widely dispersed in the form of mass health education and media campaigns. The different ethnicities highlighted in this research reside in other geographical locations within our country and also form ethnic minorities in different countries. The findings of this research can be applied to such communities living abroad. Appropriate

\begin{tabular}{|c|c|c|c|}
\hline \multirow[t]{2}{*}{ Variable } & \multicolumn{3}{|c|}{$\begin{array}{l}\text { Respondents agreeing } \\
\qquad(n=2030)\end{array}$} \\
\hline & No. & $\%$ & $95 \% \mathrm{Cl}$ \\
\hline $\begin{array}{l}\text { Smokeless tobacco has carcinogenic tendencies and can cause oral cancers and } \\
\text { cancers of other body organs }\end{array}$ & 251 & 12.3 & $10.8-13.7$ \\
\hline Smokeless tobacco use can lead to cardiovascular disease & 15 & 0.7 & $0.3-1.1$ \\
\hline Smokeless tobacco used can lead to adverse outcomes of pregnancy & 9 & 0.4 & $0.1-0.7$ \\
\hline Smokeless tobacco can lead to dental diseases & 223 & 11.0 & $9.6-12.4$ \\
\hline Smokeless tobacco has no associated health implications & 692 & 34.1 & 31.9- 36.1 \\
\hline Don't know or have no relevant knowledge & 840 & 41.4 & $38.9-43.1$ \\
\hline
\end{tabular}

$\mathrm{Cl}=$ confidence interval. 
health interventions should be designed to prevent smokeless tobacco use which should be culturally and ethnically adapted.

The findings of this research suggest that tobacco control policies need to encompass and address smokeless tobacco consumption and not just focus on cigarettes. This could involve incorporating questions about smokeless tobacco consumption into national surveys Moreover, research into effective policies and cessation support options should be conducted with prime focus on the provisions of the WHO Framework Convention on Tobacco Control. More research is required to investigate the social determinants of smokeless tobacco use among the different ethnic minorities and the constituents of the smokeless tobacco products consumed in the country

Competing interests: None declared.

\section{References}

1. Boffetta P, Hecht S, Gray N, Gupta P, Straif K. Smokeless tobacco and cancer. Lancet Oncol. 2008 Jul;9(7):667-75. PMID:18598931

2. Gupta PC, Ray CS. Smokeless tobacco and health in India and South Asia. Respirology. 2003 Dec;8(4):419-31. PMID:14708551

3. Boffetta P, Aagnes B, Weiderpass E, Andersen A. Smokeless tobacco use and risk of cancer of the pancreas and other organs. Int J Cancer. 2005 May 10;114(6):992-5. PMID:15645430

4. Critchley JA, Unal B. Health effects associated with smokeless tobacco: a systematic review. Thorax. 2003 May;58(5):435-43. PMID:12728167

5. Connolly, GN, Winn DM, Hecht SS, Henningfeild JE, Walker B Jr \& Hoffman D. the re-emergence of smokeless tobacco. N Engl J Med. 1986 Apr 17;314(16):1020-7.

6. Everett SA, Husten CG, Warren CW, Crossett L, Sharp D. Trends in tobacco use among high school students in the United States, 1991-1995. J Sch Health. 1998 Apr;68(4):137-40. PMID:9644605

7. Vainio H, Weiderpass E. Smokeless tobacco: harm reduction or nicotine overload? Eur J Cancer Prev. 2003 Apr;12(2):89-92. PMID:12671531

8. Shah SM, Merchant AT, Luby SP, Chotani RA. Addicted schoolchildren: prevalence and characteristics of areca nut chewers among primary school children in Karachi, Pakistan. J Paediatr Child Health. 2002 Oct;38(5):507-10. PMID:12354270

9. Khawaja MR, Mazahir S, Majeed A, Malik F, Merchant KA, Maqsood M, et al. Chewing of betel, areca and tobacco: perceptions and knowledge regarding their role in head and neck cancers in an urban squatter settlement in Pakistan. Asian Pac J Cancer Prev. 2006 Jan-Mar;7(1):95-100.

10. Rozi S, Akhtar S. Prevalence and predictors of smokeless tobacco use among high-school males in Karachi, Pakistan. East Mediterr Health J. 2007 Jul-Aug;13(4):916-24. PMID:17955775

11. Khan SM1, Gillani J, Nasreen S, Zai S. Cancer in north west Pakistan and Afghan refugees. J Pak Med Assoc. 1997 Apr;47(4):1224. PMID:9145643

12. Zakiullah, Saeed M, Muhammad N, Khan SA, Gul F, Khuda F, et al. Assessment of potential toxicity of a smokeless tobacco product (naswar) available on the Pakistani market. Tob Control. 2012 Jul;21(4):396-401. PMID:21642445

13. Khan SM, Nasreen S, Zai S. Naswar (snuff) dipping and oral cancer in north-west Pakistan. In: Lu R, Mackay J, Niu S, Peto $\mathrm{R}$, editors. Tobacco: the growing epidemic. Proceedings of the Tenth World Conference on Tobacco or Health, 24-28 August 1997, Beijing, China. London: Springer; 2000.

14. Mazahir S, Malik R, Maqsood M, Merchant KA, Malik F, Majeed A, et al. Socio-demographic correlates of betel, areca and smokeless tobacco use as a high risk behaviour for head and neck cancers in a squatter settlement of Karachi, Pakistan. 'Subst Abuse Treat Prev Policy. 2006 Apr 26;1:10.

15. Krishnamurthy S, Ramaswamy R, Trivedi U, Zachariah V. Tobacco use in rural Indian children. Indian Pediatr. 1997 Oct;34(10):923-7. PMID:9567556

16. Vaidya SG, Vaidya NS, Naik UD. Epidemiology of tobacco habits in Goa, India. In: Gupta PC, Hamner JE III, Murti PR, editors. Control of tobacco-related cancers and other diseases. Proceedings of an International Symposium, TIFR. Bombay, January 15-19, 1990. Oxford: Oxford University Press; 1992.

17. Alam AY, Iqbal A, Mohamud KB, Laporte RE, Ahmed A, Nishtar S. Investigating socio-economic-demographic determinants of tobacco use in Rawalpindi, Pakistan. BMC Public Health. 2008;8:50. 10.1186/1471-2458-8-50 PMID:18254981

18. Nishtar S, Wierzbicki AS, Lumb PJ, Lambert-Hammill M, Turner $\mathrm{CN}$, Crook MA, et al. Waist-hip ratio and low HDL predict the risk of coronary artery disease in Pakistanis. Curr Med Res Opin. 2004 Jan;20(1):55-62.

19. Khawaja MR, Mazahir S, Majeed A, Malik F, Merchant KA, Maqsood M, et al. Chewing of betel, areca and tobacco: perceptions and knowledge regarding their role in head and neck cancers in an urban squatter settlement in Pakistan. Asian Pac J Cancer Prev. 2006 Jan-Mar;7(1):95-100.

20. Rozi S, Akhtar S. Prevalence and predictors of smokeless tobacco use among high-school males in Karachi, Pakistan. East Mediterr Health J. 2007 Jul-Aug;13(4):916-24. PMID:17955775

21. Strobe checklist for cross sectional studies [Internet]. Bern, Switzerland: STROBE (http://www.strobe-statement.org/ fileadmin/Strobe/uploads/checklists/fileadmin/Strobe/uploads/checklists/STROBE_checklist_v4_cross-sectional.pdf, accessed 4 April 2014).

22. Lanata CF, Black RE. Lot quality assurance sampling techniques in health surveys in developing countries: advantages and current constraints. World Health Stat Q. 1991;44(3):133-9.

23. Giovino GA, Mirza SA, Samet JM, Gupta PC, Jarvis MJ, Bhala $\mathrm{N}$, et al.; GATS Collaborative Group. Tobacco use in 3 billion individuals from 16 countries: an analysis of nationally representative cross-sectional household surveys. Lancet. 2012 Aug 18;380(9842):668-79. PMID:22901888

24. Country fact sheets Pakistan-Karachi (ages 13-15). Global Youth Tobacco Survey (GYTS) [Internet]. Geneva: World Health Organization; 2010 (http://www.emro.who.int/images/stories/tfi/documents/GYTS_FS_PAK_R2.pdf, accessed 4 April 2014).

25. Rural population in Pakistan. Trading Economics [Internet] (http://www.tradingeconomics.com/pakistan/rural-population-wb-data.html, accessed 4 April 2014). 